\title{
Diş tedavisinde kullanılan post core sistemin yaklaşık çözüm yöntemleri kullanılarak optimum tasarımı
}

\author{
Optimum design of post core system used in dental treatment using approximate solution \\ methods
}

Oğuz KAYABAȘI*1,a

${ }^{1}$ Düzce Üniversitesi, Mühendislik Fakültesi, Biyomedikal Mühendisliği Bölümü, 81620, Düzce

• Geliş tarihi / Received: 08.05.2020 • • Düzeltilerek geliş tarihi / Received in revised form: 23.01.2021 • Kabul tarihi / Accepted: 19.02 .2021

\begin{abstract}
Öz
Post core tedavisi, çok fazla risk taşıyan bir tedavi olması nedeniyle yüksek başarısızlık riski olan bir tedavidir. Bu nedenle, post core şeklinin optimizasyonu büyük önem taşımaktadır. Başarısızlık riski, zayıf noktaların keşfedilmesi ve optimize edilmesiyle azaltılabilir. Post core şeklinin tasarımı, mühendisler ve cerrahlar arasında yakın iş birliği gerektiren karmaşık bir süreçtir. Çok dayanıklı post core tasarlamak için, çene kemiğinde meydana gelen doğal süreçleri hesaba katmak gerekir. Post core tasarımındaki en önemli faktörlerden biri post core da, çene kemiğinde ve dişte meydana gelen gerilmeleri azaltmaktır. Post core testlerin in vivo gerçekleștirilmesinin zorluğu nedeniyle, yapısal modelleri yürütmek için matematiksel modeller geliştirilmiştir. Bu çalışmada post core sisteminin statik ve dinamik yükler altındaki etkileri sonlu elemanlar metodu ile incelenmiş, ilk olarak 3D modellemesi yapılmıştır. Analizler, farklı malzemeden yapılmış elemanların geometrik özelliklerle optimize edilmesiyle yapılmışır. Sonuçlar karşılaştırılmış ve post çekirdeklerin potansiyel zayıflıkları analiz edilmiştir. Bu çalı̧̧mada, post core tasarımı için etkili ve otomatik bir tasarım stratejisi önerilmiştir. Bu stratejide, Sonlu Elemanlar Analizi, Yaklaşık model ve sayısal bir optimizasyon algoritması, otomatik bir tasarım aracı oluşturmak için entegre edilmiştir. Bu yaklaşımı kullanarak, post core'un şekil tasarımı, geleneksel bir sayısal optimizasyon algoritması ile kolayca çözülebilen bir optimizasyon problemi şeklinde formüle edilebilir. Bu, tasarım için zaman kazandıracak ve post core sisteminin hastaya yanlış uygulanmasından kaynaklanan kalıcı hasarları önleyecektir.
\end{abstract}

Anahtar kelimeler: Post core sistem, Sonlu elemanlar analizi, Yaklaşık çözüm yöntemi

\begin{abstract}
Post-core therapy is a treatment with a high risk of failure due to the high risk of treatment. For this reason, optimization of the post core shape is of great importance. Failure risk can be reduced by discovering and optimizing weak points. The design of the post-core shape is a complex process that requires close cooperation between engineers and surgeons. In order to design a very durable post core, it is necessary to take into account the natural processes occurring in the jawbone. One of the most important factors in post-core design is to reduce stresses in post-core, jawbone and tooth. Because of the difficulty of performing post-core tests in vivo, mathematical models have been developed to carry out structural models. In this study, the effects of post core system under static and dynamic loads were examined with finite element method and firstly $3 D$ modeling was done. The analyzes were made by optimizing the geometric properties of the elements made of different materials. The results were compared and potential weaknesses of the post cores were analyzed. In this study, an effective and automatic design strategy for post core design is proposed. In this strategy, Finite Element Analysis, Approximate model and a numerical optimization algorithm, are integrated to create an automated design tool. This will save time for design and prevent permanent damage caused by improper application of the post core system to the patient.
\end{abstract}

Keywords: Post core system, Finite element analysis, Approximate solution techniques

*a Oğuz KAYABAŞI; oguzkayabasi@duzce.edu.tr, Tel: (0380) 542 10 36, orcid.org/0000-0003-0129-1113 


\section{Giriş}

Endodontik olarak tedavi edilen dişlerin restorasyonu hala tartışmalı bir konudur ve vital dişlere göre daha yüksek biyomekanik yetmezlik riskine sahip olduklarından, bunları düzeltmek için en etkili yolu seçerken özel dikkat gösterilmektedir. (Llena vd., 2001, Fennis vd., 2002, Testori vd., 1993). Restorasyon sonras1 dişlerin kırılma direnci sayısız in vitro ve in vivo çalışmanın konusu olmuştur (Martinez vd., 1998, Darendeliler vd., 1998, Yang vd., 2002, Isidor vd., 1999, Heydecke vd., 2002, De Castro Albuquerque vd., 2003, Lanza vd., 2005, Genevose vd. 2005). Dişler ve restorasyonlarda gerilme ve gerinim dağılımlarını değerlendirmek ve klinik başarısızlık riski altında olan tahmini alanları varsaymak için FEA ile farklı yükleme koşulları değerlendirilebilir (Sahafi vd., 2005, Zarone vd., 1998). Restoratif teknikle ilgili en iyi bakış açıları literatürde bulunabilir, ancak in vivo çalışmalar genellikle klinik olarak mevcut olan ve kırık direncinde çok yüksek standart sapmalara neden olan birçok değişkeni kontrol edemez. Ayrıca, bir in vitro deneyde kullanılan statik yükleme in vivo durumun temsilcisi olmayabilir. Dinamik yükleme daha geçerli gibi görünmektedir, ancak birçok çalışmada bir kırığın kayıt altına alınması için gerçekçi olmayan yüksek yükler kullanılmaktadır. İn vitro çalışmalardan elde edilen sonuçların büyük değişkenliğinden dolayı, dübel-restore edilmiş dişlerin birçok araştırması sonlu elemanlar analizine (SEA) dayanmaktadır (Assif ve Gorfil 2005, Stockton vd., 1998, Baratieri vd., 2000, Assif vd., 2003). Bazı araşatırmacılar dentin ve çimentodaki düğümlerin her bir bağlayıcı için sabit bir bağlanma dayanımı belirlemişlerdir (Daisuke vd., 2019, Ona vd., 2013, Ploumaki vd., 2013, Mojtaba vd., 2017, Kalay vd., 2016, Kayabaşı vd., 2006). Bir restoratif sistem, yükleme olduğunda, kendine özgü gerilme ve gerinim dağılımları üreten kuvvetleri absorbe edebilir. Örneğin, Sonlu Elemanlar Analizi kullanılarak bu gibi modellerin değerlendirilmesi, olası mekanik arıza riski altındaki alanları tahmin etmek için güvenilir bir öngörü parametresi olabilir. Sadece mine ve dentin değil, aynı zamanda kemik dokuları, periodontal ligamanın ve yapıştırıcı ara yüzlerinin mekanik olarak karakterize edilmesi mümkündür. Restorasyonlar içindeki stres dağılımlarını değerlendirmek ve klinik başarısızlık riski altında olan tahmini alanları varsaymak için farklı yükleme koşulları SEA ile değerlendirilebilir. Sanal benzetimlerden elde edilen veriler in vitro sonuçlar ile doğrulanmalıdır ve benzetim edilmiş matematiksel modellerin doğrulanması için laboratuvar incelemeleri kullanılmalıdır

$\mathrm{Bu}$ çalışmada, post core tasarımı için etkili ve otomatik bir tasarım stratejisi önerilmiştir. $\mathrm{Bu}$ stratejide, Sonlu Elemanlar Analizi, Yaklaşık model ve sayısal bir optimizasyon algoritmas1, otomatik bir tasarım aracı oluşturmak için entegre edilmiştir. Bu yaklaşımı kullanarak, post core'un şekil tasarımı, geleneksel bir sayısal optimizasyon algoritması ile kolayca çözülebilen bir optimizasyon problemi şeklinde formüle edilebilir. $\mathrm{Bu}$, tasarım için zaman kazandıracak ve post core sisteminin hastaya yanlış uygulanmasından kaynaklanan kalıcı hasarları önleyecektir.

\section{Materyal ve yöntem}

\subsection{Sonlu elemanlar modeli}

Ağız içi fiziki şartların analizinin yapılabilmesi için post core sisteminin bilgisayar ortamında modellenmesi gerekir. 3 aşamadan meydana gelen sonlu elemanlar modelinde ilk aşamada geometrik modelin oluşturulmasıdır. Bu çalışmada geometrik model CAD programı olan Pro/Enginer WildFire 5.0 kullanılarak oluşturulmuştur. Geometrik model oluşturulduktan sonra IGES formatında sonlu elemanlar modelinin oluşturulması için ANSYS 18.1 APDL sonlu elemanlar analiz programına aktarılmıştır. Sadece mine ve dentin değil, aynı zamanda kemik dokuları, periodontal ligamanın mekanik olarak karakterize edilmesi için birebir ağız içinin sonlu elemanlar modeli oluşturulmuştur. Sonlu elamanlar modelinde iç kemik için ortotropik malzeme modeli $\left(\mathrm{E}_{\mathrm{x}}=\right.$ $\mathrm{E}_{\mathrm{y}}=11.5 \mathrm{GPa}, \mathrm{E}_{\mathrm{z}}=17 \mathrm{GPa} ; \mathrm{G}_{\mathrm{xy}}=3.6 \mathrm{GPa}, \mathrm{G}_{\mathrm{xz}}=$ $\left.\mathrm{G}_{\mathrm{yz}}=3.3 \mathrm{GPa} ; v_{\mathrm{xy}}=0.51, v_{\mathrm{xz}}=v_{\mathrm{yz}}=0.31\right)$ diş kemik için isotropik malzeme modeli $(\mathrm{E}=2.13 \mathrm{GPa}$ ve v=0.3) kullanılmıştır (Kayabaşı vd., 2006, Kayabaşı, 2020). Modelde kullanılan diğer malzeme özellikleri Tablo 1 'de verilmiştir. Modelde yer alan temas yüzeyleri arasındaki fiziksel etkileşimler, temas-çarpma algoritmaları kullanılarak simüle edilmiştir.

$\mathrm{Bu}$ temas elemanları, yüzeyler arası sürtünmenin kullanılmasına izin verir. Post ve yapıştırıcı ara yüzü bağlanmış temas tipi olarak modellenmiştir. Aşağıda belirtildiği gibi üç farklı tip temas algoritması kullanılmıştır (Kayabaşı vd., 2006).

1-Bonded temas algoritmas1

2-Debonded temas algoritmas $\mu=0.22$

3-Debonded temas algoritmas $\mu=0$ 
Tablo 1. Malzeme özellikleri

\begin{tabular}{lccc}
\hline \multicolumn{1}{c}{ Malzeme } & $\begin{array}{c}\text { Elastik modülü } \\
(\boldsymbol{G P A})\end{array}$ & $\begin{array}{c}\text { Poisson oranı } \\
(\mathbf{v})\end{array}$ & Referans \\
\hline Enamel & 1.97 & 0.669 & Hansen (1990) \\
Pulp & 2.65 & 0.844 & Hansen (1990) \\
Dentin & 18.6 & 0.310 & Hansen (1990) \\
Periodontal Ligament & 0.0689 & 0.450 & Testori (1993) \\
Gutta percha & 0.00069 & 0.450 & Testori (1993) \\
Porselen diş & 120 & 0.280 & Testori (1993) \\
Titanyum post & 112 & 0.330 & Llena (2001) \\
Cam fiber post & 40 & 0.260 & Llena (2001) \\
Karbon fiber post & 125 & 0.250 & Llena (2001) \\
Zirkonyum post & 200 & 0.330 & Fennis (2001) \\
Yapıştırıc1 & 22 & 0.350 & Fennis (2001) \\
\hline
\end{tabular}

Sonlu elemanlar modelinde ikinci aşama sınır şartlarının oluşturulmasıdır. Şekil 1 (a)'da gösterildiği gibi çiğneme esnasında oluşan 3 yöndeki kuvvetler porselen dişin yüzeyine uygulanmıştır. Çiğneme esnasında meydana gelen
3 yöndeki kuvvetler, dinamik etkilerin de hesaba katılması için 5 saniyelik kuvvet-zaman eğrisiyle oluşturulmuştur. Kuvvet-Zaman eğrisi Şekil 1 (b)'de gösterilmektedir.
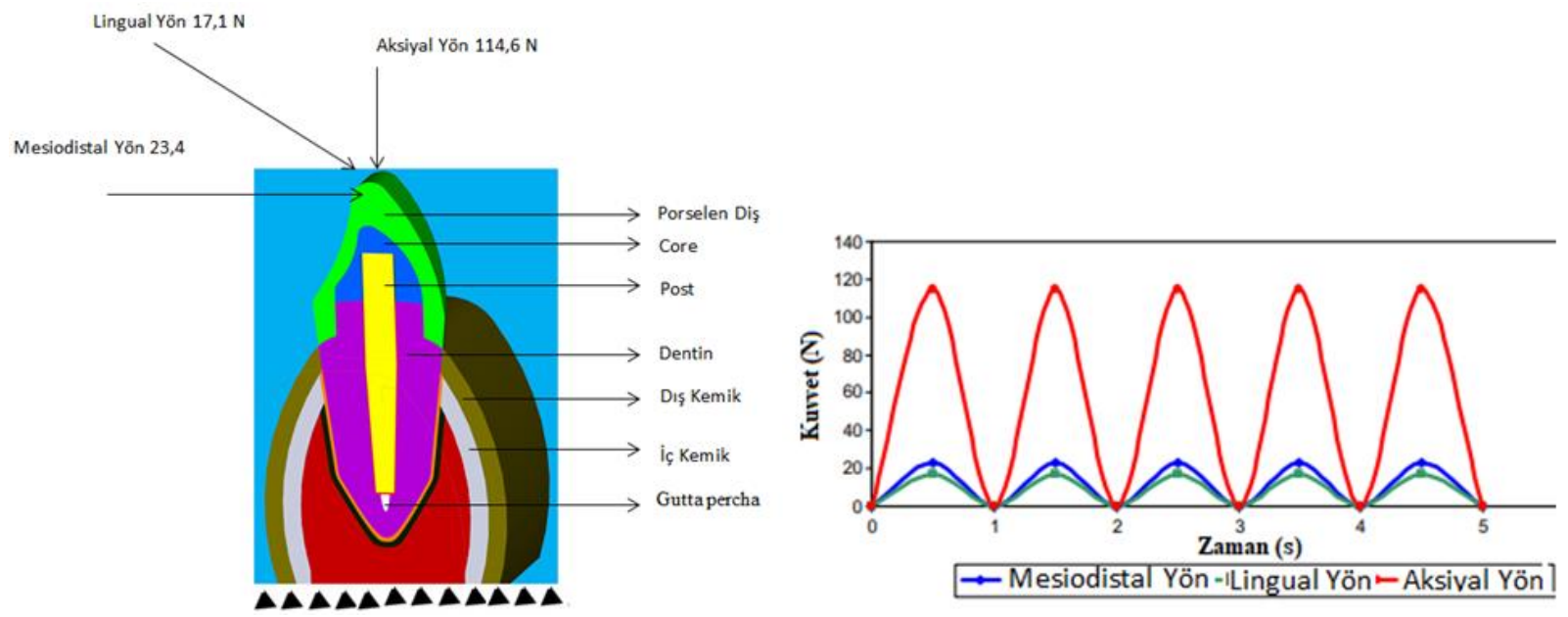

Şekil 1. Sınır Şartları (a) Yüklerin uygulanması (b) Kuvvet-Zaman Eğrisi

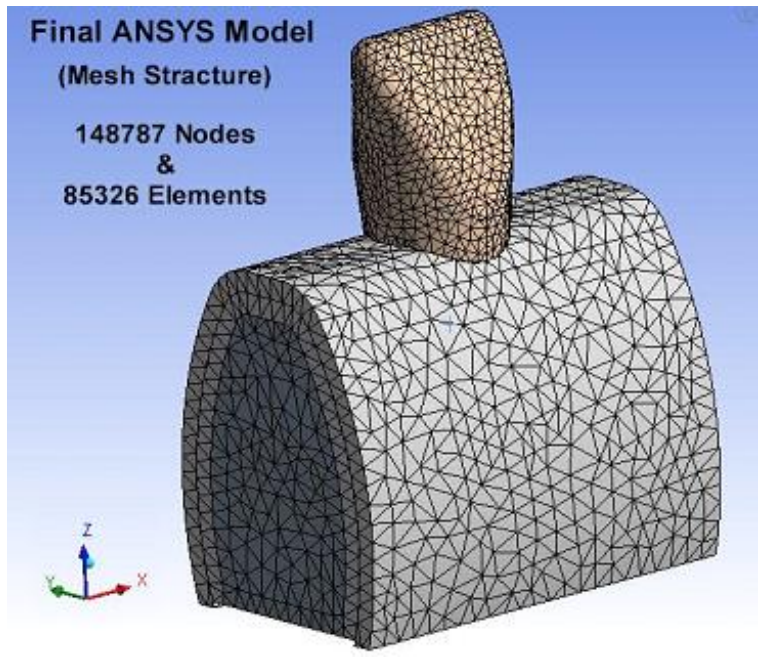

Şekil 2. Sonlu elemanlar modeli

\subsection{Parametrik model}

Geometrik şekiller, post core sisteminin performans1 üzerinde büyük etkiye sahiptir. Gerilme konsantrasyonu seviyesi ve yorulma başarısızlığı eğilimi, gövde yüzeylerinin açısallığına bağlıdır. Bu çalışmada, düşük gerilme değerleri ve yüksek yorulma ömrü sağlayacak bir post core geometrisi araştırılmıştır. $\mathrm{Bu}$ amaca ulaşmak için, post core ANSYS Parametrik Tasarım Dili (APDL) kullanılarak parametrik olarak modellenmiştir. Parametrik modelde kullanılan parametreler, tasarım parametreleri olarak adlandırılır ve Şekil 3 'te gösterilmektedir. En iyi post core şekli (boyutlar) bu parametrelerin ayarlanmasıyla bulunur. Şekil 3'teki D1, D2 ve L1 'in tasarım değişkenleri geometriyi açıklar. Şekil 3'teki D1, D2 ve L1 tasarım değişkenleri olup 
parametrik modeli açıklar. Okuyucuya, tasarım parametrelerinin sayısı arttıkça, daha iyi post core şekli (yani daha iyi performans) olacağının hatırlatılması faydalı olacaktır. Bununla birlikte, en iyi post core tasarımını bulmak için ihtiyaç duyulan analiz sayısı (yani hesaplama maliyeti), seçilen tasarım parametrelerinin sayısı ile doğrusal veya kuadratik olarak orantılı olacaktır.

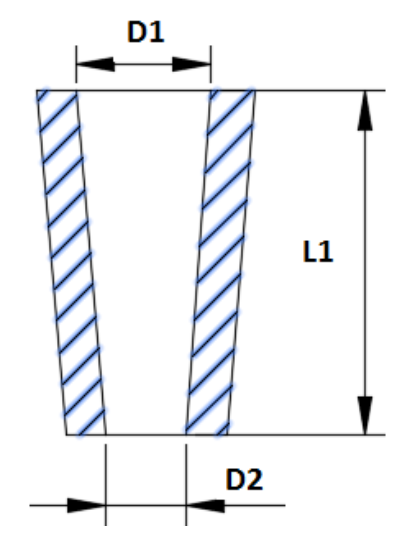

Şekil 3. Parametrik model

En iyi (optimum) post core geometrisi veya şekli için arama işlemi, amaç ve gereksinimler, aşağıdaki gibi bir optimizasyon problemi tanımı biçiminde ifade edilirse, sayısal bir optimizasyon algoritması aracılığıyla otomatikleştirilebilir.

Tasarım parametrelerini bul:

$$
D 1, D 2, L 1
$$

Tasarım amacını minimize et:

Maksimum gerilme (von Mises gerilme)

Tasarım kısıtlamaları:

$\sigma_{\text {post şekli }} \leq \sigma_{\text {post şekli }}^{\text {akma }}$

$\sigma_{\text {yap } 1 s ̧ t ı r ı c 1} \leq \sigma_{\text {yapıştırıc1 }}^{\text {akma }}$

$\sigma_{\text {çene kemiğ } i} \leq \sigma_{\text {çene kemiğ } i}^{\text {akma }}$

$\tau_{\text {yapıştırıc1-post core }} \leq \tau_{\text {yapiștırıcı-post core }}^{\text {hata }}$

Tasarım aralığı:

$1 \mathrm{~mm} \leq D 1 \leq 2.5 \mathrm{~mm}$

$0.6 \mathrm{~mm} \leq D 2 \leq 1.5 \mathrm{~mm}$

$7 \mathrm{~mm} \leq L 1 \leq 12 \mathrm{~mm}$

Denklem (1), post core sistemini geometrisini/şeklini tanımlayan tasarım parametrelerini gösterir. Denklem (2), tüm post core sistemi üzerinde meydana gelen maksimum gerilmeyi en aza indiren tasarım amacını temsil eder. Denklemler (3-6), post core sistemi bileşenlerinde yapısal ve yorulma mukavemeti limitleri üzerindeki tasarım kısıtlamalarına karşılık gelir. Denklemler (9-11), parametrelerin aranacağ 1 tasarım alanını temsil eder. Tasarım alanının sinırları, deneyime ve literatüre dayanarak belirlenir. Denklemler (2-6)'daki amaç ve kısıtlama işlevleri, optimizasyon probleminin çözümünden önce açıkça (analitik olarak) bilinmemektedir. Farklı post core şekillerine karşılık gelen belirli sayıda rastgele seçilmiş tasarım parametre değeri için Sonlu elemanlar analiz sonuçlarına en küçük karesel uydurma uygulanarak oluşturulurlar. Amaç ve kısıtlama fonksiyonlarının yaklaşımları kullanıldığg için, optimizasyon yöntemi bazen yaklaşık optimizasyon yöntemi olarak adlandırılır ve yaklaşımlar yanıt yüzey yaklaşımı veya yanıt yüzey modelleri olarak adlandırılır. Lineer ve kuadratik polinom fonksiyonlar genellikle amaç ve kısıtlama fonksiyonlarının cevap yüzey yaklaşımlarını oluşturmak için kullanılır. ANSYS DO modülünde uygulanan ve bu çalışmada kullanılan yaklaşı optimizasyon yöntemi Şekil 4 'te gösterilmiştir.

Bir şekil tasarım optimizasyonu problemi genellikle kisitlı bir minimizasyon problemi olarak formüle edilebilir.

minimize

$y_{0}(x)$

amaç:

$y_{j}(x) \leq 0 \quad\left(j=1, \ldots, n_{c}\right)$

tasarım aralığ 1

$x_{i j} \leq x_{i} \leq x_{i u} \quad(i=1, \ldots, N)$

Amaç fonksiyonu, $y_{0}(\mathbf{x})$, kısıtlama işlevleri ve tasarım değişkenlerinin vektörü $y_{j}(\mathbf{x}) j=1, \ldots, n_{c}$ ve $\mathbf{x}=\left[x_{1}, x_{2}, \ldots, x_{N}\right]$ tasarım değişkenlerinin vektörüdür. $x_{i l}$ ve $x_{i u}$ tasarım değiş̧kenleri üzerindeki fiziksel üst ve alt sınırları tanımlar. $n_{c}$ ve $N$ sirasiyla kisitlamaların sayısı ve tasarım değişkenlerinin sayısıdır. Şekil optimizasyonu için Denklemlerin Çözümü (10) - (12), objektif ve kısitlama fonksiyonlarının Tepki Yüzeyi (YY) yaklaşımlarıyla değiştirilmesiyle verimli bir şekilde yapılabilir. Yaklaşımlarla optimizasyon, genellikle literatürde yaklaşık optimizasyon olarak ifade edilir. ANSYS DO modülünde uygulanan ve bu çalışmada kullanılan yaklaşık optimizasyon 
yöntemi Şekil 4'te gösterilmiştir. ANSYS DO modülü, nesnel ya da kısıtlama işlevi için polinom YY yaklaşımı üretir ve kullanır.

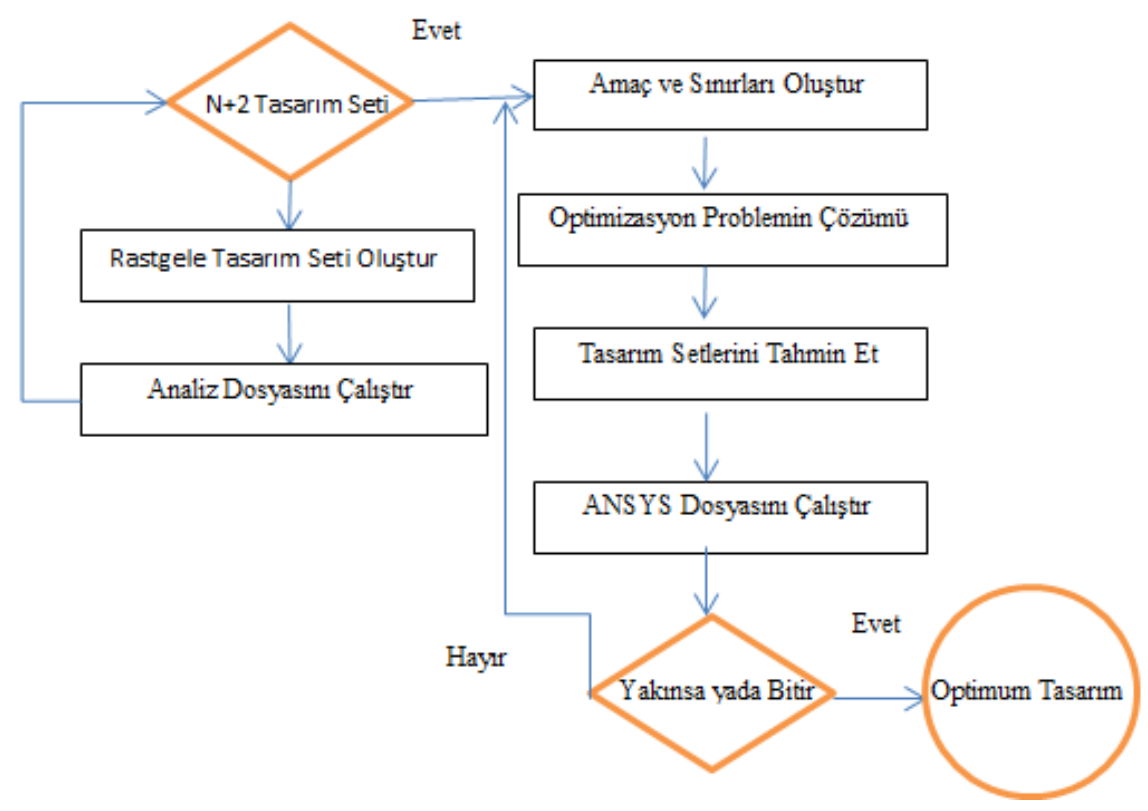

Şekil 4. Optimizasyon Akış Şeması

\section{Bulgular}

Optimizasyon sürecinde meydana gelen maksimum gerilme değerleri ve tasarım optimizasyon yöntemi kullanılarak tasarım parametreleri için optimizasyon grafikleri Şekil 57'de gösterilmiştir. Şekil 5'te çene kemiğinde meydan gelen maksimum gerilme değerlerin post için 4 farklı malzeme kullanıldığında optimizasyon sürecinde meydana gelen değerleri göstermektedir. Şekil 6'da post şeklinde meydana gelen maksimum gerilme değerlerin iterasyonla değişimi gösterilmektedir.
Şekil 7'de tasarım değişkenlerinin iterasyonla değişimini göstermektedir. Optimum post geometrisi, 50 optimizasyon iterasyonundan sonra bulunmuştur. Şekil 8'de gösterilmiştir. Hesaplama maliyetini düşürmek için optimizasyon süreci 50 iterasyonla sınırlandırılmıştır. Daha fazla yineleme daha iyi bir tasarım sağlayabilir. Optimum şekil, gerilme değerlerini en aza indirir ve postun yorulma ömrünü en üst düzeye çıkarır. Şekil 8'den optimum post şeklinin D1 çapının $2.3 \mathrm{~mm}$, D2 çapının $1.5 \mathrm{~mm}$ ve $\mathrm{L} 1$ boyunun $10 \mathrm{~mm}$ olduğu görülmektedir.

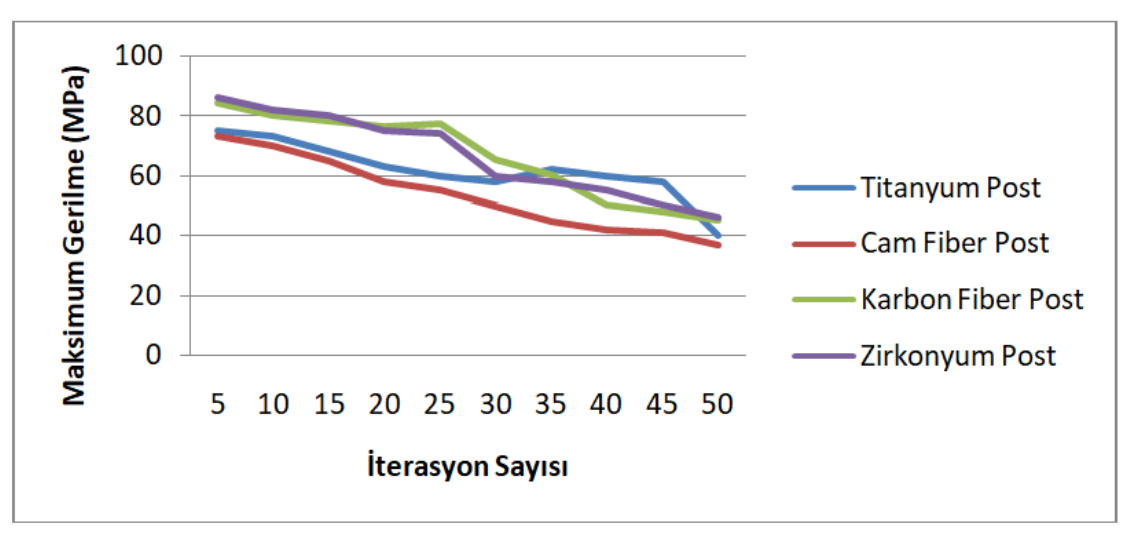

Şekil 5. Çene kemiğinde meydana gelen maksimum değerlerin iterasyonla değişimi 


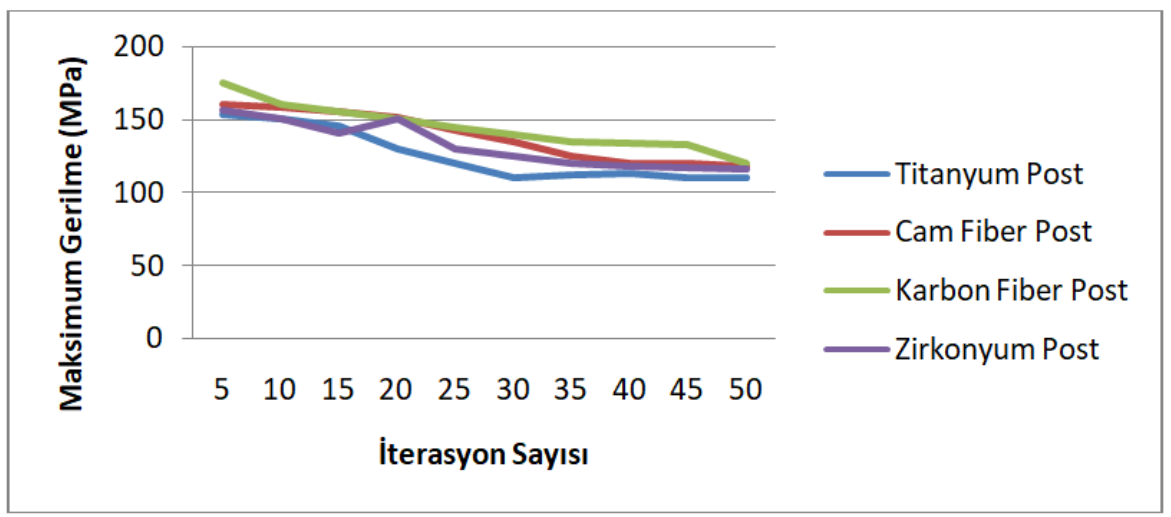

Şekil 6. Post şeklinde meydana gelen maksimum değerlerin iterasyonla değişimi

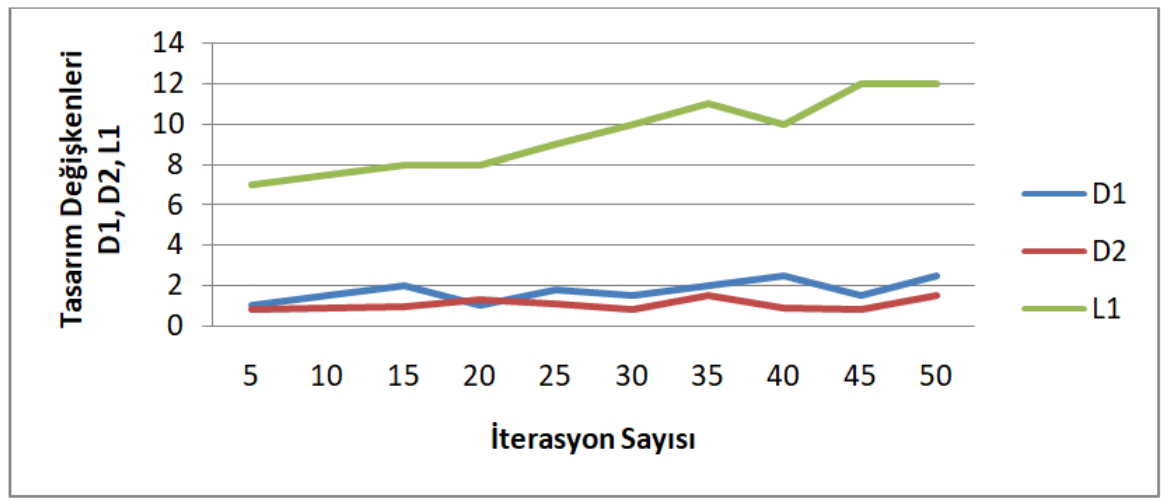

Şekil 7. Tasarım değişkenlerinin iterasyonla değişimi

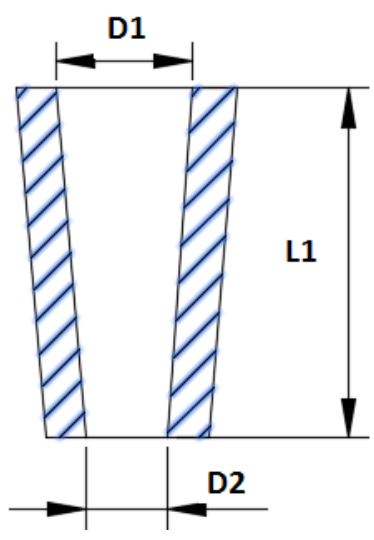

Şekil 8. Optimum post şekli

Çene kemiğinde gelen gerilme, post şekli üzerinde meydana gelen gerilme değerine göre daha azdır. Tek tek parçalar için sonuçları karşılaştırmak için, boyutsuz bir parametre kullanılmalıdır. $\mathrm{Bu}$ parametre stres/akma gerilmesi olarak seçilmiştir. Tablo 2'de değerler görülmektedir.

Post core sistemlerinde tasarım analizi yapılırken post ile çene kemiği arasında kullanılan yapıştırıcının da analiz edilmesi gerekir. Postun diş kökünde sağlam bir şekilde durmasını sağlayan yapıştırıcıdır. Öyleki yapıştırıcı ve post ara yüzü iyi irdelenmelidir. Bu ara yüzde meydana gelen mikro çatlaklar zamanla ilerleyerek postun kök içinde sağlam durmasını engelleyecek ve zamanla çiğnemenin etkisiyle postun kırılmasına neden olacaktır. Bu amaçla kullanılan 3 farklı ara yüz modelinde oluşan gerilmeler Şekil 9 ve 10 'da gösterilmektedir. Bonded temas algoritması kullanilan modelde meydana gelen gerilme değerleri diğer kullanılan Debonded temas algoritmas1 $\mu=0,22$ sürtünme katsayısına sahip ve Debonded temas algoritması $\mu=0$ sürtünme katsayısına sahip modelde meydana gelen gerilme değerleri daha düşüktür. Şekil 9'da üç farklı ara yüz modeli oluşturularak çene kemiğinde meydana gelen gerilme değerleri ile Şekil 10'da post şekli üzerinde meydana gelen gerilme değerleri gösterilmektedir. Sonlu elemanlar analizi, araştırılan parametreler değiştiğinde diş restorasyon kompleksinde indüklenen gerilmelerde önemli değişiklikler gösterdi. Sadece mine ve dentin değil, aynı zamanda kemik dokuları, periodontal ligament ve üç boyutlu katı elemanlar kullanılarak yapıştırıcı ara yüzlerini mekanik olarak karakterize etmemizi mümkün kıldı. Farklı yükleme koşulları altında, dişler ve diş restorasyonlarında meydana gelen gerilme ve gerinim dağılımlarını değerlendirmemize olanak sağladı. Klinik başarısızlık riski altında olan tahmin bölgelerini hipotezlememize yardımcı oldu. 
$\mathrm{Bu}$ çalışma, optimizasyon tekniklerinin ve farklı malzeme modellerinin, ara yüzde meydana gelen gerilmelerin azaltılması için optimize edilmiş post core sisteminin bileşen tasarımlarını elde etmek için tamamen 3-boyutlu gerilme analizi modeli ile birleştirilebileceğini göstermektedir.

Tablo 2. Boyutsuz parametre

\begin{tabular}{lc}
\hline \multicolumn{1}{c}{ Parça } & Gerilme/Akma gerilmesi \\
\hline Titanyum post & 0.184 \\
Cam fiber post & 0.154 \\
Karbon fiber post & 0.215 \\
Zirkonyum post & 0.189 \\
Çene kemiği (Titanyum post) & 0.126 \\
Çene kemiği (Cam fiber post) & 0.181 \\
Çene kemiği (Karbon fiber post) & 0.176 \\
Çene kemiği (Zirkonyum post) & 0.153 \\
\hline
\end{tabular}

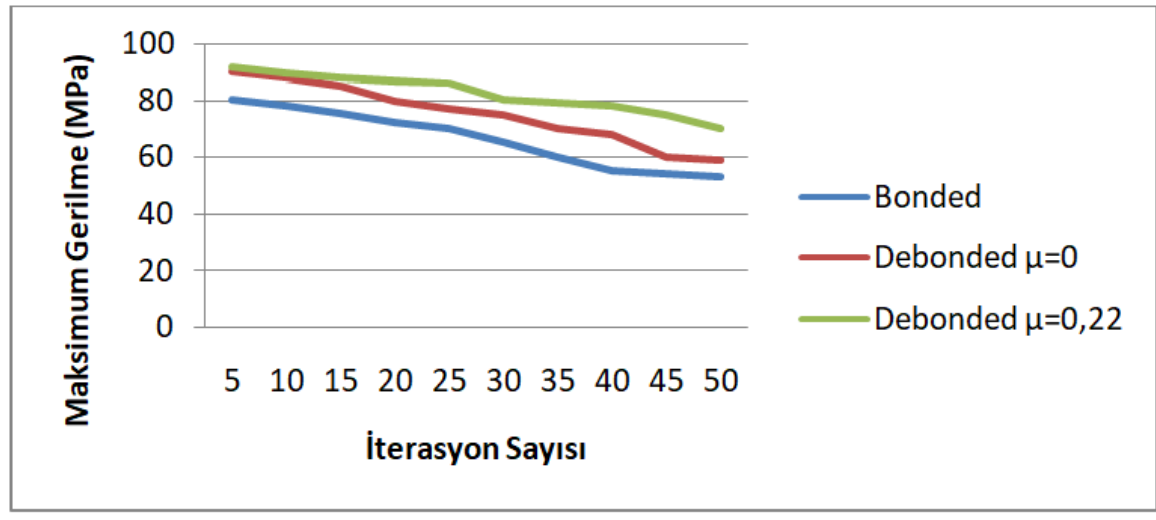

Şekil 9. Çene kemiğinde meydana gelen gerilme (3 farklı arayüz şartlarında)

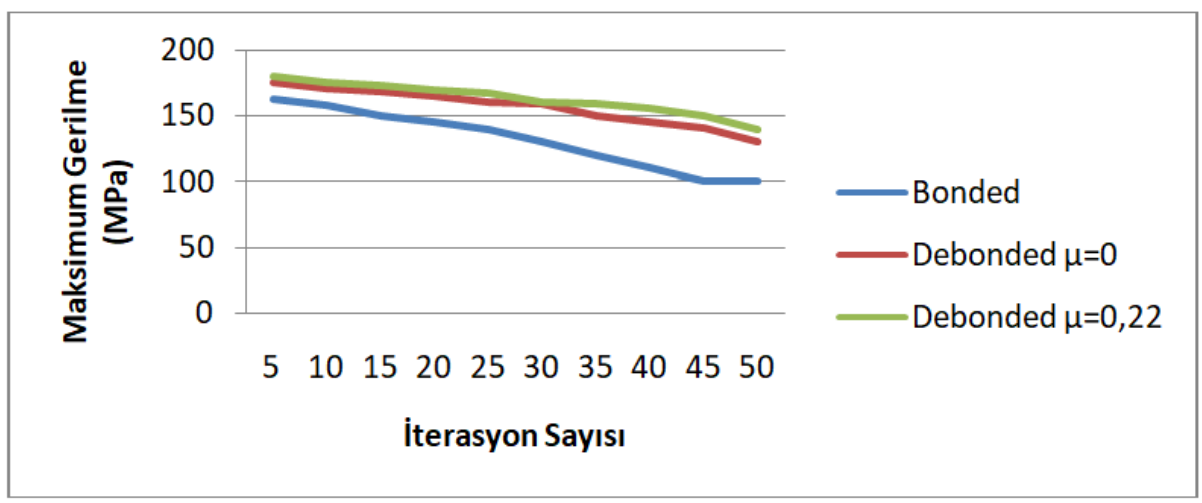

Şekil 10. Post şekli üzerinde meydana gelen gerilme ( 3 farklı arayüz şartlarında)

\section{Tartışma ve sonuç}

Sonlu elemanlar analizi, karmaşı yapılarda gerilme dağılımlarının hesaplanmasında güçlü bir araçtır. Daha önce belirtildiği gibi, yöntem varyasyon olmadan sonuç sağlar. Bununla birlikte, çalışmanın geçerliliği, modelin gerçekliğe yaklaşma derecesine bağlıdır. Sonlu elemanlar analizi, incelenen parametreler değiştiğinde diş restorasyon kompleksinde indüklenen streslerde önemli değişiklikler olduğunu gösterdi. Üç boyutlu katı elementler kullanarak yalnızca enamel ve dentin değil aynı zamanda kemik dokuları, periodontal ligament ve yapışkan arayüzleri mekanik olarak karakterize etmek mümkündür. Fonksiyonel yüklemede, maksimum eşdeğer gerilme çoğunlukla yapıştırıcı tabakasının vestibüler tarafında meydana gelir. Bukkal boydan yatay yükleme artmış ve dikey yükler maksimum gerilmeyi azaltmıştır.

Yapıştırılmış restorasyonların yapışkan ara yüzleri oklüzal kuvvetleri kalan diş yapılarına homojen olarak iletir ve dağıtır ve kırılmaya karşı direncini 
arttırır. Öte yandan, farklı elastikiyet modüllerine sahip malzemelerin ara yüzleri, tokluk uyumsuzluğu stres dağılımını etkilediğinden restoratif sistemin zayif noktasını temsil etmektedir. Dentin tabakada biyomekanik özelliklere sahip bir post core, dişlerin kök kırılma riskini azaltarak avantajlı olabilir. Dişin doğal fonksiyonuna karşı çalışan çok sert bir post core hem dentin içinde, hem de kemik çimentosu ve direkte ara yüzeylerinde gerilme ve kayma bölgeleri oluşturur. Bu çalışmada, düşük elastik modüllü bir yapışkan reçine çimentosu ile bağlanmış cam elyaf post core ile minimum gerilme değerleri elde edilmiştir.

Cam ve karbon post core, yüksek yorulma ve çekme dayanımı sergilerler ve dentin'yle karşılaştırılabilecek bir Young modülüne sahiptirler. Ayrıca, bu direkler yapışkan kanallı çimento ile kök kanalına yapıştırılabilir. Bağlanma ajanları post ile kök yapısı arasında stres ileterek, stres konsantrasyonunu azaltır ve kırılmayı önler. Post core ve çimento arasında ve çimento ile dentin arasında bağlanma, endodontik restorasyonların optimum davranışını sağlamak için önemli bir parametre olarak görünmektedir. Aksine, çelik post core ve geleneksel çimentolar homojen bir stres dağılımına izin vermez. Çimento yapışmasının en zayıf bileşen olduğuna inanılmaktadır ve bu bileşendeki kırılma, kompleks yapıdaki gerilme dağılımında değişikliklere neden olmaktadır. Test edilen hipotez, protez uygulanmış dişlerin çimento kırma işlemlerinin post-ve core'ların elastik özelliklerinden etkilendiği şeklinde olmuştur.

Genel bir sonuç, post core sistemini hastaya uygulanmadan önce bilgisayar modelleri ile tasarlanıp çalışılabilmesidir. Bu prosedür, tasarım süresini azaltırken yanlış yapılan uygulamanın neden olduğu kalıcı hasarı önlemeye yardımcı olur.

\section{Kaynaklar}

Assif, D., Nissan J., Gafni Y. and Gordon M., (2003). Assessment of the resistance to fracture of endodontically treated molars restored with amalgam. Journal of Prosthetic Dentistry, 89, 462-475. https://doi.org/10.1016/S00223913(02)52748-7

Assif, D. and Gorfil, C., (1994). Biomechanical considerations in restoring endodontically treated teeth. Journal of Prosthetic Dentistry, 71, 565-577.https://doi.org/10.1016/00223913(94)90438-3

Baratieri, L.N., De Andrada M.A., Arcari G.M. and Ritter, A.V., (2000). Influence of post placement in the fracture resistance of endodontically treated incisors veneered with direct composite. Journal of Prosthetic Dentistry, 84, 180-184. https://doi.org/10.1067/mpr.2000.108415

Daisuke, T., Teruo, I., Hidetoshi, O., Tomonori, I. and Masanori, F., (2019). Influence of elastic modulus mismatch between dentin and post-andcore on sequential bonding failure. Journal of Prosthodontic Research, 63, 227-231. https://doi.org/10.1016/j.jpor.2018.12.003

Darendeliler, S.Y., Alacam, T. And Yaman, Y., (1998). Analysis of stress distribution in a maxillary central incisor subjected to various post and core applications. Journal of Endodonty, 24, 107- 111. https://doi.org/10.1016/S0099-2399(98)80087-3

De Castro, A.R., De Abreu, L.T., Fontana, T.S. and Cimini, C.A., (2003). Stress analysis of an upper central incisor restored with different posts. Journal of Oral Rehabilation, 30, 936-943. https://doi.org/10.1046/j.13652842.2003.01154.x

Fennis, W.M., Kuijs, R.H., Kreulen, C.M., Roeters, F.J., Creugers, N.H. and Burgersdijk, R.C., (2002). A survey ofcusp fractures in a population of general dental practices. International Journal of Prosthodontic, 15, 559- 563.

Genovese, K., Lamberti, L. and Pappalettere, C., (2005). Finite element analysis of a new customized composite post system for endodontically treated teeth. Jornal of Biomechanics, 38, 2375-2389. https://doi.org/10.1016/j.jbiomech.2004.10.009.

Hansen, E.K., Asmussen, E. and Christiansen, N.C., (1990). In vivo fractures of endodontically treated osterior teeth restored with amalgam. Endodonti Dental Traumatology, 10, 49-55. https://doi.org/10.1111/j.16009657.1990.tb00389.x

Heydecke, G., Butz, F., Hussein, A. and Strub, J.R., (2002). Fracture strength after dynamic loading of endodontically treated teeth restored with different post and core systems. Journal of Prosthetic Dentistry, 87, 438-445. https://doi.org/10.1067/mpr.2002.123849

Isidor, F., Brondum, K. and Ravnholt, G., (1999). The influence of post length and crown ferrule length on the resistance to cyclic loading of bovine teeth with prefabricated titanium posts. International Journal of Prosthodontic, 12, 78-82.

Kalay, T.S., Yildirim, T. andUlker, M., (2016). Effects of different cusp coverage restorations on the fracture resistance of endodontically treated maxillary premolars. Journal of Prosthetic Dentistry, 116, 404-10. https://doi.org/10.1016/j.prosdent.2016.02.007 
Kayabaşı, O., Yüzbasığlu, E., ve Erzincanlı, F., (2006). Static, dynamic and fatigue behaviors of dental implant using finite element method. Advances in Engineering Software, 37, 649-658. https://doi.org/10.1016/j.advengsoft.2006.02.00 4

Kayabasi O., (2020). Design methodology for dental implant using approximate solution techniques. Journal of Stomatology, Oral and Maxillofacial Surgery, $\quad 121, \quad 684-695$. https://doi.org/10.1016/j.jormas.2020.01.003

Lanza, A., Aversab, R., Rengob, S., Apicellaa, D. and Apicella, A., (2005). 3D fea of cemented steel, glass and carbon posts in a maxillary incisor. Dental Materials, 21, 709-715. DOI: 10.1016/j.dental.2004.09.010

Llena, M.C., Forner, L. and Barbero, I., (2001). Vertical root fracture in endodontically treated teeth: a review of 25 cases. Oral Surgery Oral Medical Oral Pathology Oral Radiolgy Endodonlogy, 92, 553-565.

https://doi.org/10.1067/moe.2001.117262

Martinez, A., da Silva L., Rilo, B. and Santana, U., (1998). Comparison of the fracture resistances of pulpless teeth restored with a cast post and core or carbon-fiber post with a composite core. Journal of Prosthetic Dentistry, 80, 527-532. https://doi.org/10.1016/s0022-3913(98)70027-7

Mojtaba, M., Reza S., Parviz A. and Maryam A.H., (2017). Influence of in homogeneous dental posts on stress distribution in tooth root and interfaces three-dimensional finite element analysis. The Journal of Prosthetic Dentistry, 6, 742-751. https://doi.org/10.1016/j.prosdent.2017.01.002
Ona, M., Wakabayashi, N., Yamazaki, T., Takaich, i A. and Igarashi, Y., (2013). The influence of elastic modulus mismatch between tooth and post and core restorations on root fracture. International Endodontology, 46, 47-52. https://doi.org/10.1111/j.13652591.2012.02092.x

Sahafi, A., Peutzfeldt, A., Ravnholt, G., Asmussen, E. and Gotfredsen, K., (2005). Resistance to cyclic loading of teeth restored with posts. Clinical Oral Investigation, 9 , 84-90. https://doi.org/10.1007/s00784-004-0299-7

Stockton, L., Lavelle, C.L., ve Suzuki M., (1998). Are posts mandatory for the restoration of endodontically treated teeth? Endodontic Dentistry Traumatology, 14, 59-63. https://doi.org/10.1111/j.16009657.1998.tb00810.x

Testori, T., Badino, M. and Castagnola, M., (1993). Vertical root fractures in endodontically treated teeth: a clinical survey of 36 cases. Journal of Endodontology, 19, 87-91. https://doi.org/10.1016/S0099-2399(06)81202-1

Yang, H.S., Lang, L.A., Guckes, A.D. and Felton D.A., (2002). The effect of thermal change on various dowel-and-core restorative materials. Journal of Prosthetic Dentistry, 86,74-80. https://doi.org/10.1067/mpr.2001.115503

Zarone, F., Apicella, D., Sorrentino, R., Ferro, V., Aversa, R. and Apicella, A., (2005). Influence of tooth preparation design on the stress distribution in maxillary central incisors restored by means of alumina porcelain veneers: a 3d-finite element analysis. Dental Materials, 21,1178-1188. https://doi.org/10.1111/jopr.13121 